\title{
Design and Test of Flipped Classroom Learning Support Model in Mobile Learning Environment
}

\author{
Xiulin Ma${ }^{1}$, Youyuan Su${ }^{1}$, Jingjing Liu ${ }^{1 *}$, Sheng $\mathrm{Li}^{2}$ \\ ${ }^{1}$ Faculty of Education, Beijing Normal University, Beijing, China \\ ${ }^{2}$ The Joint Laboratory for Mobile Learning, Ministry of Education, China Mobile Communication Corporation, Beijing, China \\ Email: maxl@bnu.edu.cn, 583745194@qq.com, *1069321995@qq.com, lisheng@chinamobile.com
}

How to cite this paper: Ma, X. L., Su, Y. Y., Liu, J. J., \& Li, S. (2019). Design and Test of Flipped Classroom Learning Support Model in Mobile Learning Environment. Creative Education, 10, 246-261. https://doi.org/10.4236/ce.2019.102020

Received: January 7, 2019

Accepted: February 10, 2019

Published: February 13, 2019

Copyright $\odot 2019$ by author(s) and Scientific Research Publishing Inc. This work is licensed under the Creative Commons Attribution International License (CC BY 4.0).

http://creativecommons.org/licenses/by/4.0/

\begin{abstract}
The coverage of wireless network and the popularization of mobile communication devices enable mobile learning to happen anytime and anywhere; short and refined micro-course resources are more popular in mobile learning environments, and the flipped classroom teaching mode based on mobile learning environment also presents a more extensive application momentum. However, flipped classroom teaching practice based on mobile learning environment has also encountered some problems in recent years, mainly manifested as unstable knowledge system of learners and short retention time of learning motivation. This study referred to the existing flipped classroom teaching model; discussed the characteristics and problems of learning resources in mobile learning environment, and put forward the teaching design idea of "further structuring micro-learning resources, visualizing knowledge system and giving full play to teachers' dominance with the help of instant messaging tools" in the mobile learning environment. With the help of practical teaching activities, the value of this design idea in improving the learning efficiency of flipped classroom was verified, and a relatively stable "flipped classroom learning support model under mobile learning environment" was finally formed. Finally, the relevant theories of mobile learning environment supporting autonomous learning are improved.
\end{abstract}

\section{Keywords}

Mobile Learning Environment, Flipped Classroom, Micro-Lecture Resource, Learning Support Model

\section{Introduction}

\subsection{The Flipped Classroom Model Is Conducive to the Development of Innovative Ability}

According to the outline of the national program for medium- and long-term 
talent development (2010-2020), China urgently needs schools at all levels and types to cultivate comprehensive talents with strong independent innovation ability and collaboration ability, but at present, the traditional "the teacher speaks-the students listen" teaching mode implemented in Chinese schools is obviously difficult to meet this demand.

Throughout the current teaching mode of primary and secondary schools, the teacher is still the master of the classroom, and students are the passive and audience in the process. From the efficiency of knowledge transfer, we can't deny the positive effect of this mode. However, students in this mode are in a state of passive learning in the process of acquiring knowledge; they are just like a baby being fed by a nanny to acquire knowledge. Although students already have some knowledge accumulation at this time, many students are obviously deficient in active retrieval and acquisition of knowledge, independent exploration and induction (He, Li, Xie, \& Wang, 2000).

Compared with the traditional teacher-centered teaching model, flipped classroom teaching provides students with a platform for independent exploration and learning. And it also encourages students to "forage" rather than "feed" during the learning process, which plays a significant role in cultivating students' ability to explore and innovate. Flipped classroom teaching is very beneficial for cultivating students' self-management ability, time management ability, collaboration ability, communication ability and anxiety management ability. Flipped classroom conforms to the national strategic goal of cultivating innovative talents (Ma et al., 2017). Therefore, no matter in primary and secondary schools or universities, flipped teaching shows a more extensive and promising application momentum.

\subsection{Mobile Learning Environment Provides Important Support for Flipped Classroom Teaching}

Mobile learning refers to a new digital learning form that uses wireless mobile communication network technology and wireless mobile communication devices (mobile phones, iPad, etc.) to obtain education information, education resources and education services (Ye \& Xu, 2004).

Since its wide application, mobile learning has been integrated with MOOC learning activities and flipped classroom teaching mode, which has become an important guarantee for the smooth development of MOOC learning activities and flipped classroom teaching mode. With the popularity of WiFi and mobile devices, and the decline of $3 \mathrm{G}$ and $4 \mathrm{G}$ fees, more and more learners use mobile devices to carry out autonomous learning in the new knowledge self-learning stage of flipping classroom, and have achieved good results (Hwang, Lai, \& Wang, 2015).

It is a feature of flipped classroom that students learn new knowledge independently before class with the help of learning platform. Under the mobile learning environment, short and concise micro-course resources with a certain 
knowledge point as the theme have been more widely accepted and applied. In addition, communication software supported by mobile devices gradually plays an important role in the learning process of learners and becomes an important communication tool in the learning process of learners.

\subsection{Problems in Flipped Classroom Teaching Supported by Mobile Learning Environment}

Although flipped classroom based on mobile learning environment has great advantages in promoting the development of students' innovative ability and changing the traditional teaching-centered teaching mode, many unsatisfactory conditions have occurred in the specific teaching practice, which directly affect the teaching quality of flipped classroom. The reasons for the problems in flipped classroom are analyzed in the following aspects.

Firstly, inertia and free riding exist in flipped classroom teaching organization. Students' autonomous learning of new knowledge before class with the help of learning platform is the characteristic of flipping classroom. However, in the specific teaching practice, there is a widespread problem that learners' learning enthusiasm and initiative are not strong, and learners' learning motivation is gradually weakening. This phenomenon is particularly prominent when flipping classroom teaching is carried out in the lack of teacher-led MOOC platform (Tsai et al., 2017).

Secondly, in the mobile learning environment, fragmented micro-learning resources such as micro-video are used more often, which is likely to lead to the fragmentation of learners' knowledge system, and is not conducive to the formation of a solid knowledge system for learners. In addition, randomly or linearly arranged micro-resources make the connection between knowledge points be separated, which is not conducive to the transition, connection and transfer of knowledge and the formation of systematic and correlated knowledge construction among students.

Third, learners in pure resource-oriented platforms have a lower sense of learning efficiency and motivation due to their failure to get timely feedback on their learning behaviors and learning effects. Because the independent learning of new knowledge in the early stage fails to meet the standards, it will eventually affect the quality of class report and discussion. Some students with strong inertia even become "bystanders" and "hitchhikers" in class discussion and collaboration.

\subsection{Research Questions}

Based on the composition and organization of micro-resource packages in the mobile learning environment and the interaction supported by mobile communication devices, this study combined its theoretical development and teaching practical experience to form and verify the flipped classroom teaching model in the mobile learning environment to support the effective implementation of 
flipped classroom teaching. The research questions in this study are mainly focused on the following three aspects.

1) According to the teaching practice, supplement and perfect the constitution of micro-course resource package. In order to enable students to choose the appropriate type of learning resources to learn according to their own learning needs and learning characteristics.

2) According to the teaching practice, this paper explores the organizational mode of micro-course resource package, hoping that the new organizational mode can help learners establish the logical relationship between knowledge points, promote the transfer of knowledge and stimulate the intrinsic motivation of learners.

3) Pay attention to the interaction and collaboration of independent learning, this paper intend to construct the interactive environment based on mobile learning environment, and explore its benefit for maintaining learners' learning motivation. As the result, it can make sure higher collaboration quality.

\section{Literature Review}

\subsection{Research on Flipped Classroom}

1) Definition and characteristics of flipped classroom

The basic idea of flipped classroom teaching is to reverse the traditional learning process, so that students can complete independent learning of knowledge points and concepts after class. Classroom becomes an interactive place between teachers and students, mainly used to solve doubts, report and discuss, so as to achieve better teaching results (Ma, Zhao, \& Wu, 2016). Flipped classroom breaks the traditional teaching mode of active teaching by teachers and passive listening by students, and highlights the teaching thought of "student-centered", which conforms to the learning theory of constructivism about "active construction" and "meaningful construction".

2) Education value of flipped classroom

As a new teaching mode, FCM arranges the learning of new knowledge outside the classroom. This classroom requires students to independently arrange their learning content and progress according to their knowledge base and understanding of knowledge points. At the stage of independent learning, students are required to consult materials and explore effective strategies to solve difficult problems. FCM provides a good opportunity for students to carry out self-exploration and self-management (Nouri, 2016).

a) FCM provides a platform for students to explore and study independently

FCM returns the "initiative" originally belonging to students' active learning to students, respects the right of learners to organize the learning process independently, promotes learners to "forage" independently rather than "feed" all the way through the learning process, exercises the wild nature of students' independent "foraging", and gradually makes this wild nature an instinct for students' independent learning and self-exploration. The formation of force is of 
great significance (Nouri, 2016).

b) FCM is conducive to the improvement of students' overall capacity

In order to analyze the influence of FCM on students' comprehensive quality, the author has led the computer basic course teaching team of Beijing normal university to conduct quantitative research for five consecutive years, and used LASSI scale to investigate and analyze the influence of FCM on students' learning attitude and comprehensive quality development. According to the research, FCM promotes the improvement of students' comprehensive quality in the following five aspects. Firstly, FCM makes for cultivating students' self-management ability. Secondly, FCM is conducive to cultivating students' time management ability. Thirdly, FCM benefits the cultivation of students' cooperative ability. Fourthly, FCM is good for the cultivation of students' communication skills. Fifth, FCM is good for cultivating students' anxiety management ability ( $\mathrm{Ma}$, Lei, \& Zhang, 2017).

c) The application of FCM benefits the realization of national talent training strategic goals

While most Chinese students are still used to passive learning, the education value of FCM is not reflected in the efficiency of knowledge transfer, but in the cultivation of students' "independent inquiry ability", "time management ability", "self-management ability", "communication ability" and "anxiety management ability". These are exactly the elements that every creative talent must have. Therefore, the application of FCM is conducive to the realization of national talent training strategic objectives.

3) Research on flipped classroom learning support model

The main characteristics of the flipped classroom are that students complete the learning of new knowledge before class, report, discuss and question in class, so as to realize the flipped classroom. The most important condition for the success of flipped classroom is that students should conduct in-depth and effective autonomous learning before class. Therefore, a high-quality learning support system is very necessary.

From the perspective of flipped classroom teaching practice, the resources used by students for independent learning before class mainly include various micro-resource packages and text-based book materials provided by the teaching platform. Among them, micro guidance, micro video and micro courseware are the most common forms of resources. Compared with the static single text materials and a large number of network resources with different strengths and weaknesses, various micro-course resource packages play a key role in the learning process of students, which can be provided on the teaching platform based on mobile terminals and used anytime and anywhere.

In 2010, the teaching team of the author started to explore the teaching of college computer basic courses based on the flipped classroom teaching model. In 2013, the author proposed the flipped classroom teaching model based on the learning support platform, as shown in Figure 1. As the initial exploration 


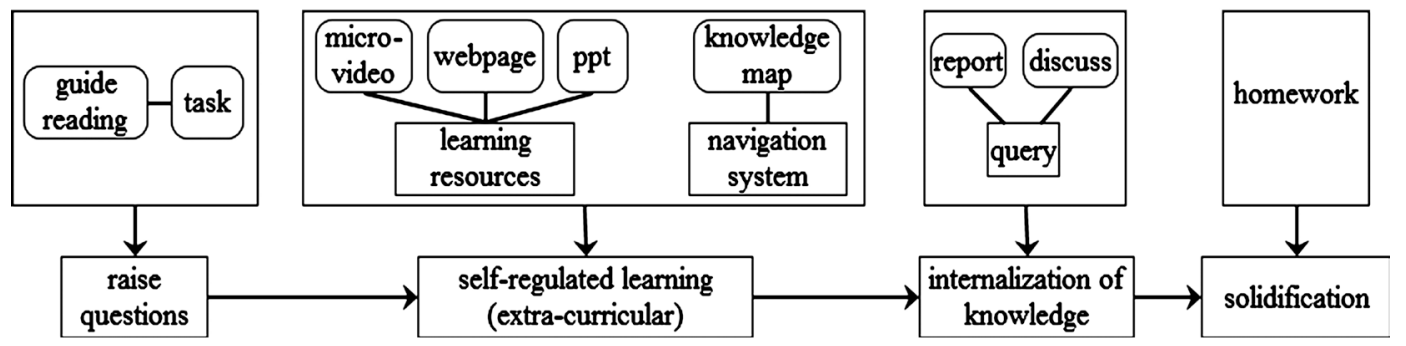

Figure 1. Flipped classroom learning support model (Ma, Zhao, \& Wu, 2013).

period, this stage formed a relatively brief structure, which include four stages of flipped classroom teaching mode, and the strategies for autonomous learning support are not elaborate enough.

\subsection{Research on Mobile Learning}

Mobile learning has such prominent characteristics as flexible learning style and learning behavior can occur at anytime and anywhere. In mobile learning environment, students can search for real-time answers to difficult questions, and search for various types of learning resources, rich in content and interesting, which can help stimulate students' interest and promote students' fragmentation learning (Keengwe \& Bhargava, 2014).

Compared with traditional video resources with long duration, single type and large information capacity, micro-course resources with relatively short information capacity have become a popular learning resource in the era of mobile learning, with more emphasis on miniaturization of learning content in the context of mobile learning.

In addition to real-time search of rich network learning resources in the mobile learning environment, various interactive tools on mobile devices, such as QQ or WeChat, provide students with a convenient interactive platform. Teachers and students can communicate, share and question in real time by establishing QQ group or WeChat group. Learning and communication can happen anytime and anywhere.

\subsection{Micro-Resources and Their Learning Support}

1) Internal composition of micro-resources

Khan academy in the United States provides more than 3200 micro courses (micro video) on its website, including science, medicine, medical care and other disciplines. In addition to video, it also provides more than 320 problem sets, learning situation monitoring, task area, evaluation tools and one-to-one tutoring resources (O’Donnell, 2012).

In China, the basic composition of micro-course resources can be summarized as "very $4+1$ ". " 1 " is the core resource of micro-course: a wonderful teaching video, " 4 " is to provide four teaching and learning auxiliary resources that are closely related to this teaching video (knowledge points), including micro-teaching plan (or micro-learning plan), micro-courseware (or micro-learning 
plan), micro-exercise (or micro-thinking), micro-reflection (or micro-feedback) (Hu, 2014). Zhou combined his empirical survey results with the resource composition proposed by Hu. In his opinion, in addition to micro-video, supporting resources of micro-course should mainly include: teaching design, micro-course task list, and relevant exercises, knowledge solutions, courseware, passing test, knowledge extension, etc. According to the survey, he pointed out that students have a high demand for various supporting resources, especially relevant exercises (Zhou, 2015).

2) Organization of micro-resources

Around 2010, domestic scholars put forward the theory of knowledge visualization to organize learning resources. Knowledge visualization theory points out that the so-called visualization is to enhance people's cognition of abstract information by using computer-supported, interactive and visual representation of abstract data (Ma, Zhao, \& Zhu, 2013). Knowledge visualization applies visual representations to promote the dissemination and innovation of group knowledge. The idea is to use various tools to express knowledge or the relationship between knowledge in the form of schemata and animation, so as to promote students to quickly clarify the logical relationship between knowledge points on the basis of existing knowledge structure and realize meaningful construction.

The fragmentation advocated by micro-course ignored the inherent relationship among knowledge, which to some extent resulted in students' incoherent and hindered their meaningful learning. Mind mapping can make the relationship between knowledge points reappear. On the basis of ensuring the unique advantages of micro courses, many fragmented knowledge points cut by human will present the overall structure of flowing water and integration, so that students can avoid fragmented learning and not get lost in the fragmented learning process (Xie \& Xu, 2015).

\section{Research Design and Key Issues}

\subsection{Research Ideas and Processes}

This research explored and optimized the learning resources and social construction in flipped classroom teaching. Finally, the effective learning support model was formed, which is based on theoretical development and practical exploration of micro-course resource package and interactive software in the mobile learning environment, combined with student feedback, teachers' teaching experience and objective data statistics.

The flow chart of this study is shown in Figure 2.

\subsection{Flipped Classroom Learning Support Model Based on Mobile Learning Environment}

Under the guidance of theoretical support and teaching practice, based on the original flipped classroom learning support model, the author proposed a flipped classroom learning support model for mobile learning environment. Its 


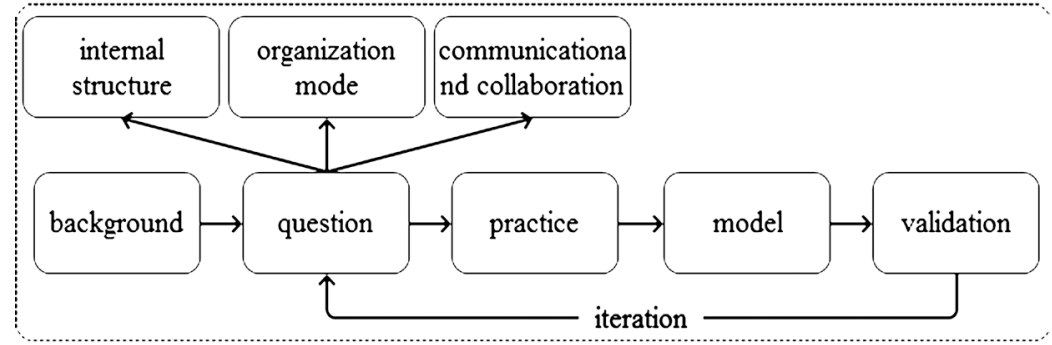

Figure 2. The flow chart.

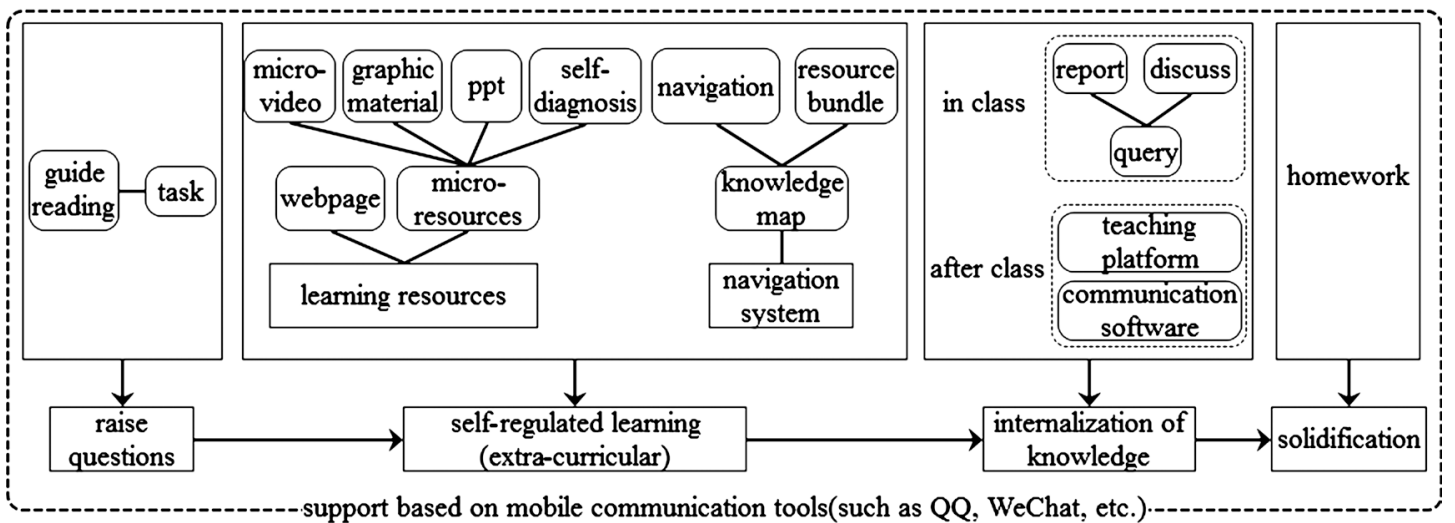

Figure 3. Flipped classroom learning support model based on mobile learning environment.

structure is shown in Figure 3.

Compared with Figure 1, Figure 3 is more accurate in learning support. In the part of learning resource support for independent learning before class, some new components are added to the micro-course resource package on the basis of micro-video, so as to facilitate students to choose appropriate learning resources at different learning stages. In the knowledge map part, in addition to the simple navigation function, the corresponding learning resources are linked to promote students' learning at any time.

In addition, in order to solve the problems students encountered in the learning process timely, the WeChat group based on mobile devices was established. WeChat group is convenient and timely to use, which can protect learners' learning enthusiasm and provide strong support for learners to carry out the next stage of learning smoothly.

With the continuous popularization of mobile learning, the communication based on mobile communication tools runs through the whole flipped classroom teaching process before, during and after class and plays a very important role in timely communication between students and teachers through multiple practices in teaching.

\section{Practice}

This research is carried out based on the course "application of modern education technology". In the learning support platform, a relatively complete learning resource system and learning activity organization mode have been gradually 
formed, which well supports learners' independent learning before class.

\subsection{Explore the Internal Structure of Micro-Resource Bundle in Mobile Learning Environment}

1) Ideas and design

At the beginning of flipped classroom research, micro-video was mainly used as a learning resource to provide support for students' learning. However, in the process of teaching practice, it was found that a single micro video could not meet the learning needs of students. Some students reported that after reading the micro video at the beginning of learning, it was no longer necessary to look at the micro video repeatedly. At this time, graphic and textual materials could present details and operational parameters more clearly. In addition, in order to enable learners to imitate the operation steps of micro video to make works, it is also necessary to provide learners with operational materials and self-diagnostic questions. Based on this assumption, the author referred to the "very $4+1$ " model of micro-course resources proposed by professor $\mathrm{Hu}$, made a structural design of micro-course resources required by flipped classroom teaching, and put forward the "picture and text material + operational material + self-diagnostic exercise" mode with micro-video as the core.

2) Teaching practice

In the learning platform of flipped classroom, the author organizes learning resources according to the principle of "micro video + graphic and text materials + self-diagnostic exercises", and organizes these resources organically. For some practical contents, the author also provides operational materials. The resource interface of "modern education technology application" module is shown in Figure 4. In the process of independent learning, learners can independently choose the resources suitable for their learning habits to carry out learning.

3) Results and discussion

In 2016, the two classes with no significant difference in pre-test both learned

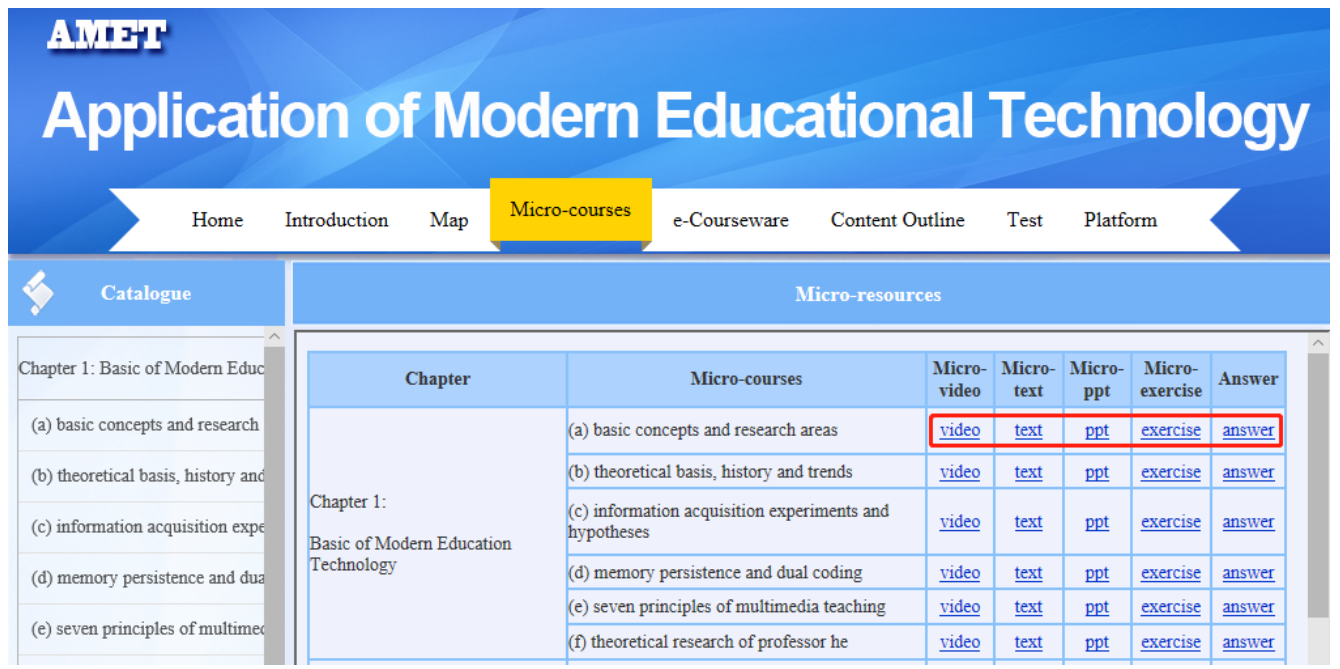

Figure 4. Micro-resources of "modern education technology foundation" module. 
the "image color adjustment" module on cen. bnu platform. Statistical data of various micro-resources used by students online are shown in Table 1 \& Table 2.

Based on the data in Table 1, the author reached the following conclusions: a) Micro-video plays an obvious role in students' independent learning, but in different types of learning modes, its role forms are obviously different. In the flipped classroom teaching mode, micro-video mainly plays a role in the early stage of learning, while in the after-class independent learning support mode, micro-video learning can occur in the entire learning cycle. b) In the independent learning based on micro-course, although micro-video is deeply loved by students, graphic and text materials have a high utilization rate. No matter flipped classroom mode of teaching or students' independent learning after class, the total number of visits to graphic and text materials exceeded the micro-video, and most of the visits to graphic and text materials were in the middle and end of the learning period. This shows that in the early stage of learning new knowledge, most students still prefer to watch micro video, but in the middle or late stage, students have a basic grasp of the learning content, and they need to master details more accurately or solve the doubts in self-diagnosis. At this time,

Table 1. Statistical data on the use of micro-resources by students in 2016 during the learning period of "Image Color Adjustment" module.

\begin{tabular}{ccccccc}
\hline & \multicolumn{6}{c}{ Independent learning support after class (97) } \\
\cline { 2 - 7 } & \multicolumn{2}{c}{ Micro video } & \multicolumn{2}{c}{ Graphic material } & Self-diagnosis & Thinking questions \\
\cline { 2 - 7 } & $\mathrm{N}$ & $\mathrm{D}$ & $\mathrm{N}$ & $\mathrm{D}$ & $\mathrm{N}$ & $\mathrm{N}$ \\
\hline Early & 21 & 87 & 2 & 23 & 0 & 0 \\
Middle & 35 & 265 & 44 & 210 & 47 & 21 \\
Last & 78 & 623 & 91 & 300 & 81 & 97 \\
Total & 134 & 975 & 137 & 533 & 128 & 118 \\
per capita & 1.38 & 10.1 & 1.41 & 5.49 & 1.32 & 1.22 \\
\hline
\end{tabular}

Table 2. Statistical data on the use of micro-resources by students in 2016 during the learning period of "Image Color Adjustment" module.

\begin{tabular}{ccccccc}
\hline & \multicolumn{5}{c}{ Flipped classroom teaching mode (105) } \\
\cline { 2 - 7 } & \multicolumn{2}{c}{ Micro video } & \multicolumn{2}{c}{ Graphic material } & Self-diagnosis & Thinking questions \\
\cline { 2 - 7 } & $\mathrm{N}$ & $\mathrm{D}$ & $\mathrm{N}$ & $\mathrm{D}$ & $\mathrm{N}$ & $\mathrm{N}$ \\
\hline Early & 109 & 803 & 2 & 31 & 11 & 0 \\
Middle & 41 & 321 & 55 & 263 & 59 & 77 \\
Last & 3 & 14 & 117 & 371 & 61 & 39 \\
Total & 153 & 1138 & 174 & 665 & 131 & 116 \\
per capita & 1.45 & 10.8 & 1.65 & 6.33 & 1.24 & 1.10 \\
\hline
\end{tabular}

Note: Early refers to the initial period of this module, Middle is the middle period of this module, Last is the closing period of this module; $\mathrm{N}$ stands for the number of students; $\mathrm{D}$ stands for the length of time, and the length of time is in minutes. 
reference to graphic materials will be more convenient and accurate. This conclusion is completely consistent with the interview results of students. c) Students' access to graphic and textual materials is complementary to the use of self-diagnostic questions. That is to say, the difficulty of self-diagnosis questions and the usage amount will directly affect the usage amount of graphic materials, but will not affect the usage amount of micro video. This conclusion also proves the importance of graphic and textual materials in solving puzzles and pursuing case details. d) Graphic and textual materials have higher efficiency in solving doubts and controlling details. As can be seen from Table 1, although the time for students to visit graphic and text materials is less than that of visiting micro-video, the number of visits to graphic and text materials is higher than that of visiting micro-video. The interview data of the students confirmed that: in the process of answering the questions (self-diagnosis questions), if the students encountered any doubt or inaccurate parameters, most of the students would directly check the picture and text materials, rather than review the micro video. Because it is faster to find information through graphic materials, the information found is more accurate. Therefore, although the visiting time of graphic materials is less than the viewing time of micro video in the long run, the amount of knowledge acquired by students relying on graphic materials is not small.

From the actual data of teaching practice, it can be seen that majority of learners will give priority to watching micro-video resources when they start to learn new knowledge. However, with the deepening of learning, most learners will turn their attention to graphic materials and self-test questions. Students responded that they could quickly obtain key information points by using graphic and textual materials when they had a preliminary grasp of knowledge. The importance of graphic materials is self-evident. The newly provided materials and self-test questions can guide learners to find problems and think deeply, and play an obvious role in consolidating new knowledge and in-depth learning.

\subsection{Exploration on the Organization Mode of Learning Resources in Mobile Learning Environment}

1) Ideas and design

Every coin has two sides, short and concise is not only the advantages of micro class, but also its short board. A single and isolated micro-course cuts and breaks knowledge points, forming an island of information, which leads to the fragmentation of knowledge system. To solve this problem, this study intends to present the knowledge structure of chapter contents with concept map under the guidance of knowledge visualization theory. With concept map (i.e. knowledge map) as the navigation, all micro resources related to each knowledge point are connected to the corresponding knowledge points of knowledge map, forming a knowledge map-based resource organization system. 


\section{2) Teaching practice}

Based on the above ideas, the author took chapters as modules to decompose knowledge points, and drew a knowledge map (i.e. concept map) that could present the logical relationship between knowledge points. And the relevant learning resources are linked to the corresponding knowledge points in the knowledge map. The knowledge map and resource organization form of "modern education technology application" module are shown in Figure 5.

As can be seen from Figure 5, the whole module is a large knowledge map, and the knowledge points involved in the module are marked as a "hand" mark in the figure. The relationships between knowledge points can be either tree-based or horizontal cross-chapter links. The corresponding micro resources of each knowledge point are presented in the form of suspension window. When the mouse hover over the "hand" tag, you can see the hyperlink of corresponding resources, including micro video, picture and text materials, self-diagnosis questions, etc.

Since 2015, the author has started to organize online independent learning activities with the help of knowledge map, requiring learners to complete independent learning of new knowledge before class with the knowledge map as the navigation. A total of 105 students (13 boys and 92 girls) used this model to carry out learning activities in 2015.

3) Results and discussion

In order to fully understand the application effect of the micro-resource system guided by the theory of knowledge visualization, the author collected the

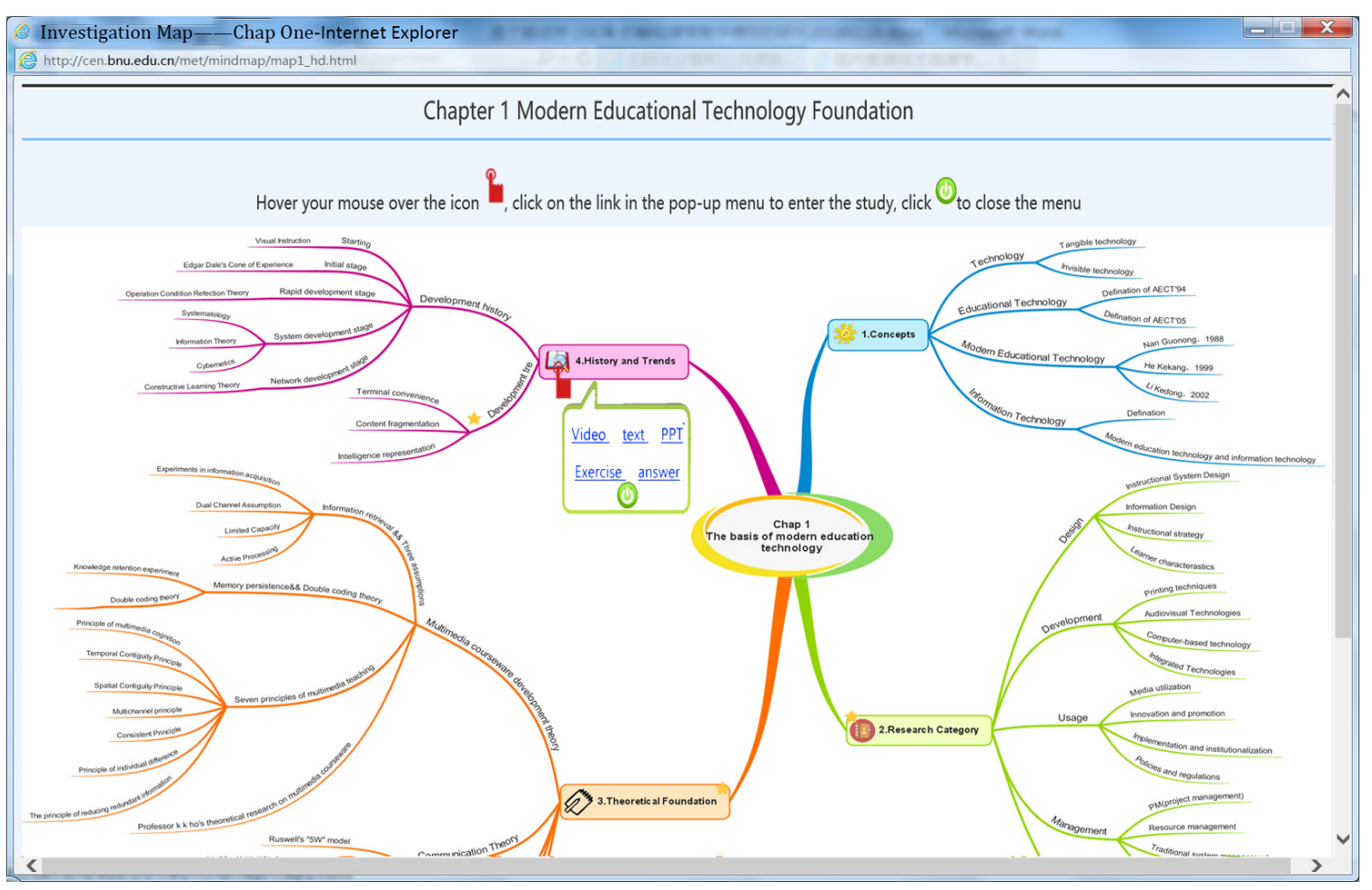

Figure 5. Micro-resources bundle organization of "modern education technology foundation" module. 
user experience of students with questionnaires and interviews respectively. Students generally think that: a) The micro-resource management system organized by using concept map as navigation map can help students to understand the prerequisite knowledge and the subsequent knowledge of each micro-resource package. This is conducive to the transfer of students from one knowledge point to another, as well as the association and positive transfer of students in the learning process, so as to avoid learning obstacles caused by insufficient knowledge of prior study. b) The learning guidance plan and thinking questions in the micro resource package play a transitional and bridge role between the micro resource packages, which is very important for inspiring thinking, guiding learning and understanding the causes and consequences of each knowledge point. c) The concept map is used to present and visualize the knowledge structure, which is beneficial for students to grasp all the contents of the whole chapter as a whole and facilitate students to find the deficiencies of their knowledge system timely and make up for the deficiencies.

In terms of classroom questions, after 2015, most students are more organized and considerate in answering classroom questions. Most students can consider the connection between cross-chapter knowledge points. However, students from 2014 and before (who were not presented navigation knowledge map) mostly answered class questions on a case-by-case basis, without considering the relevant content of previous chapters. At the same time, the quality of students' works under the group collaboration mode has also been greatly improved in the past two years.

Therefore, the learning environment based on knowledge map navigation can help students better understand the relationship between knowledge points, the precursor and the successor, can help students integrate the knowledge they have learned, more systematic, and is conducive to the occurrence of knowledge construction.

\subsection{Mobile Communication Software Support throughout the Process of Autonomous Learning}

1) Ideas and design

Relevant studies have confirmed that the establishment of learning BBS or learning community is beneficial for the interactive discussion between students, as well as the realization of social knowledge construction. Real-time interaction and feedback can also protect students' learning enthusiasm, guide students to enter the next stage of learning in a timely manner, and overcome students' learning inertia. Based on this assumption, the author believes that WeChat group based on instant messaging platform has great advantages in the learning support of flipped classroom.

Therefore, this study mainly uses the WeChat group widely used on mobile devices to organize after-class interaction and provide all-round support for learners' pre-class and after-class Q \& A and peer sharing. 


\section{2) Teaching practice}

In the fall semester of 2017-2018, the author established the WeChat group of the class for a freshman class to support the teaching of basic information processing course. In the teaching activities that lasted for a semester, students were highly motivated to use WeChat group to carry out discussions and achieved good teaching results.

3) Results and discussion

There are 53 students in this class, and the interaction with WeChat group in one semester is shown in Table 3.

From the perspective of interactive information, learners can ask questions at any time and communicate with classmates and teachers in real time, and for teachers, important notices can be issued to enable the whole class to receive them in time. More importantly, WeChat group interaction can solve the difficult problems timely in the learning process of students, which is very important to protect students' learning enthusiasm and enable them to smoothly enter the next stage of independent learning.

\section{Function and Reflection}

\subsection{Thinking about the Composition and Organization of Micro-Resources}

For graphic materials and self-diagnosis, teaching practice has proved that before the students get familiar with a practical knowledge, they will first learn through the figure, the combination of text, sound micro video for global understanding and learning. After a preliminary study and understanding, the students will complete the homework in this follow-up practice or, if met some of the steps which contain unclear or uncertain parameters, usually preferred to search material to get the answer. This relatively common phenomenon also verifies the necessity and importance of graphic and text material resources for knowledge points. For the slightly complex operational knowledge, students will generally make a timely self-diagnosis after learning the theoretical level to grasp it in a timely manner.

The visualization of knowledge structure enables learners to more clearly understand the logical relationship between various knowledge points, especially the internal logic between cross-chapter knowledge points, so that the relationship between knowledge points becomes a three-dimensional network structure. This is consistent with human thinking habits and is conducive to the construction and

Table 3. 2017 basic information processing (arts class) autumn semester WeChat communication group.

\begin{tabular}{ccccccc}
\hline & $\begin{array}{c}\text { Course } \\
\text { problems }\end{array}$ & $\begin{array}{c}\text { Computer } \\
\text { problems }\end{array}$ & Communication & Inform & Others & Total \\
\hline number & 91 & 13 & 205 & 20 & 54 & 383 \\
percentage & $23.76 \%$ & $3.39 \%$ & $53.53 \%$ & $5.22 \%$ & $14.10 \%$ & $100 \%$ \\
\hline
\end{tabular}


transfer of learners from old knowledge to new knowledge.

\subsection{Thinking about the Impact of Real-Time Communication Tools on Learning Outcomes}

Communication supported by mobile communication software is essential. Teaching practice has proved that communication in WeChat group happens almost every moment.

From the perspective of students, in the pre-class autonomous learning stage, there are many problems concerning the resources of the course, misunderstanding of the knowledge points, and even the baffle of the teaching platform (especially for freshmen), which need to be answered timely. Only by solving the current difficulties, can we have the objective conditions for moving forward, can we smoothly proceed to the next stage of learning, and the class report, discussion and communication can be of high quality and depth. In the stage of knowledge digestion and homework completion in class or after class, the teacher is eager to answer the questions that he/she does not understand or know in the homework and other related questions (such as the installation of learning software on the computer). Timely answering questions and solving doubts is of great significance for protecting learners' learning enthusiasm and maintaining their strong interest in learning.

From the perspective of teachers, the responsibility of teachers is to help students solve problems and promote learning behaviors so as to achieve the education goal. WeChat group based on instant messaging tools is very convenient for teachers to answer students' questions in real time and issue important notices and reminders (such as homework submission) from time to time. WeChat group builds a good interactive platform for teachers and students and has a good synergistic effect on teaching and learning.

At the same time, the author also found that WeChat group refresh phenomenon was quite serious in the process of WeChat group interaction. Teachers are not allowed to control the location of each post at will and do not save quality posts at will. Often, the same question is repeatedly asked and repeatedly answered, which requires teachers to pay more attention.

\section{Conflicts of Interest}

The authors declare no conflicts of interest regarding the publication of this paper.

\section{References}

He, K. K., Li, K. D., Xie, Y. R., \& Wang, B. Z. (2000). The Theoretical Basis of "Leading-Subject" Teaching Mode. E-Education Research, 2, 3-9.

$\mathrm{Hu}, \mathrm{T}$. S. (2014). Connotation Understanding and Teaching Design Methods of Micro Course (pp. 33-35). Guangdong Education (Comprehensive Edition).

Hwang, G. J., Lai, C. L., \& Wang, S. Y. (2015). Seamless Flipped Learning: A Mobile Technology-Enhanced Flipped Classroom with Effective Learning Strategies. Journal of 
Computers in Education, 2, 449-473. https://doi.org/10.1007/s40692-015-0043-0

Keengwe, J., \& Bhargava, M. (2014). Mobile Learning and Integration of Mobile Technologies in Education. Education \& Information Technologies, 19, 737-746. https://doi.org/10.1007/s10639-013-9250-3

Ma, X. L., Lei, X. Y., \& Zhang, J. Z. (2017). The Value and Misunderstanding Analysis of Education in Flipped Classroom. The Chinese Journal of ICT in Education, 1-5.

Ma, X. L., Zhao, G. Q., \& Wu, T. (2013). An Empirical Study on Flipped Classroom Teaching of College It Public Courses. Journal of Distance Education, 31, 79-85.

Ma, X. L., Zhao, G. Q., \& Wu, T. (2016). An Empirical Study on How Flipped Classroom Promotes the Development of College Students' Independent Learning Ability-Based on the Practice of Public Computer Courses in Universities. China Educational Technology, 99-106

Ma, X. L., Zhao, G. Q., \& Zhu, Y. T. (2013). Technology Realization of Knowledge Visualization and Learning Progress Visualization in LMS. China Electrochemical Education, 121-125.

Nouri, J. (2016). The Flipped Classroom: For Active, Effective and Increased Learning-Especially for Low Achievers. International Journal of Educational Technology in Higher Education, 13, 33. https://doi.org/10.1186/s41239-016-0032-z

O’Donnell, J. F. (2012). The Khan Academy: A Great Opportunity for Cancer Education. Journal of Cancer Education, 27, 395-396. https://doi.org/10.1007/s13187-012-0405-5

Tsai, C. W., Shen, P. D., Chiang, Y. C., \& Lin, C. H. (2017). How to Solve Students' Problems in a Flipped Classroom: A Quasi-Experimental Approach. Universal Access in the Information Society, 16, 1-9. https://doi.org/10.1007/s10209-016-0453-4

Xie, Y. P., \& Xu, Y. (2015). Flipped Classroom Teaching Mode in Vocational Colleges Supported by Micro-Course. Modern Education Technology, 25, 63-67.

Ye, C. L., \& Xu, F. Y. (2004). Mobile Learning and Its Theoretical Basis. Open Education Research, 23-26.

Zhou, X. B. (2015). Research on Micro-Course Construction Strategies Based on Learner's Perspective. China Electrochemical Education, 81-82+90. 